\title{
A factor analysis of data from 10 phases of sequential alternation of amygdaloid stimulation within the kindling paradigm
}

\author{
JOHN GAITO, STEPHEN T. GAITO, and JOSÉ N. NOBREGA \\ York University, 4700 Keele Street, Downsview, M3J 1P3, Ontario, Canada
}

\begin{abstract}
Data from a number of sequential alternation experiments were factor analyzed to determine the number of common factors present. Three dependent variables (latency of convulsion, number of trials to six convulsions, duration of convulsions) were evaluated by three procedures: principal components solution with $1 \mathrm{~s}$ in main diagonals, principal axes solution with largest $r$ in the diagonals, principal axes solution with $R^{2}$ in the diagonals. The results were similar; the presence of two factors was suggested in the latency and criterion measures (primary site stimulation and secondary site stimulation) and one in the duration data. A principal components factor analysis over the three dependent variables showed the presence of three factors, those observed in each of the separate analyses.
\end{abstract}

The "kindling effect" has been investigated in a number of laboratories as a model of learning, a model of epilepsy, or as an example of behavioral change of interest in its own right (e.g., Gaito \& Gaito, 1974; Goddard, McIntyre, \& Leech, 1969). The effect consists of a progressive change in the overt behavior of the animal from normal exploration (Stage $1-\mathrm{NE}$ ), to behavioral automatisms (Stage 2-BA, chewing, eye closure on ipsilateral side, salivation), and finally to clonic convulsions (Stage 3-CC) in response to electrical stimulation of a specific brain site (e.g., amygdala). Stage 3 behavior involves the rat's standing on its hind paws and the ensuing bilateral convulsions of the forelimbs. Behavioral, chemical, electrophysiological, and neurological aspects of this effect have been investigated by many researchers (Gaito, 1976a).

If one amygdala is stimulated with $50 \mu \mathrm{A}$ intensity for $5 \mathrm{sec}$ in each trial, Stage 3 is usually achieved after an average of approximately 15 trials using $24 \mathrm{~h}$ as the intertrial interval. If stimulation trials are maintained at that site until a criterion (e.g., 6 CC) is achieved and then the contralateral amygdala is stimulated, the criterion for the latter is achieved within a fewer number of trials, but increased latency to $\mathrm{CC}$ within trials results (i.e., greater time between onset of stimulation and onset of CC). Thus both positive and negative transfer occurs (Goddard et al., 1969; McIntyre \& Goddard, 1973). If the animal is now stimulated again at the primary site, it does not convulse on the first trial. A few trials are required to reach the $C C$ stage, thus indicating negative transfer.

To account for the various events in kindling, Goddard et al. (1969) and McIntyre and Goddard (1973) suggested the involvement of two effects in latency and criterion data. These are: (1) a long-term effect of a positive transfer nature, due to modified neural circuitry (Goddard et al., 1969); and (2) a short-term "aftereffect" of a negative transfer nature (McIntyre \& Goddard, 1973). The former would involve the establishment of two specific, but widespread, neural circuits. One would develop during stimulation of the primary site. During kindling of the secondary site, the second circuit utilizes and ties into response elements of the first circuit and triggers convulsions in fewer trials than were required with stimulation of the primary site. As a result of this utilization, however, the circuits are changed to correspond with the activity of the second region and lose some of their correspondence with the first one. A few trials are necessary to reestablish the original connection with the first circuit when stimulating the primary site again. The "aftereffect" would result from convulsions in both primary and secondary sites; its exact nature and mechanism are not known. The "aftereffect" was able to suppress seizure activity in different parts of the nervous system, was proportional to the number of convulsions, and spontaneously dissipated over time; complete dissipation occurred in 2 weeks or so (McIntyre \& Goddard, 1973).

Burnham (1975) also suggested that two mechanisms were involved in these kindling events. One was a convulsion mechanism that had duration as its indicator; the other was a triggering mechanism which was expressed in terms of latency. This classification was based on the fact that latency and duration results, over three sequential alternation phases, were distinctively different. Duration values remained approximately the same for each phase, whereas latencies slowly decreased over phases and within phases.

Based on Goddard and McIntyre's findings of 
positive and negative transfer effects between kindled hemispheres, we decided to extend the number of alternating stimulation phases of 10 or more (instead of just 3) to determine the point where the transfer between hemispheres would disappear and the responses for both hemispheres would become approximately the same. In general, in our experiments, we use three trials a day and stimulation at an intensity of $100 \mu \mathrm{A}$ for $30 \mathrm{sec}$ in each trial. Stimulation is maintained at one amygdala until $6 \mathrm{CC}$ are observed, then applied at the contralateral amygdala until the same criterion is attained, then reinstated at the site first stimulated, and so on, in a pattern of sequential alternation of unilateral stimulation of the two amygdalae. Under these circumstances, instead of the expected stabilization of the responses, an "oscillation effect" developed (Gaito, 1976b). This effect consisted of the occurrence of consistently low values for one amygdala and consistently high values for the other as stimulation was alternated between the two. The effect was most prominent in latency data.

A number of variables which might affect this oscillation tendency have been investigated in our laboratory. In latency data, simultaneous bilateral stimulation prior to, or after, the development of oscillation had no disruptive effect on the oscillation tendency (Gaito, 1976c). The tendency persisted with
1,3 , or 6 trials per day (Gaito, 1976d) and 1, 6, and 12 convulsions per phase (Gaito, 1976e). Oscillation was as prominent in old rats (420-475 days of age) as in younger ones (135-200 days) (Gaito \& Nobrega, 1977). Rest intervals of 1,3 , and 6 months interspersed between two sets of 10 sequential alternation phases had no deleterious effect (Gaito, 1976f). The tendency was unaffected by intensities of 100 and $280 \mu \mathrm{A}$, but $560 \mu \mathrm{A}$ intensity had a slight disruptive effect (Gaito, 1977). Thus, it appears that the oscillation effect is an extremely robust event for latency data.

In the criterion measure there are few oscillators. Each of the above manipulations disrupted partially, or completely, this weak oscillatory tendency. The duration of convulsion measure was not analyzed in these experiments because few oscillators were detected in the first study.

There are two main types of oscillation which occur consistently in our research. Primary oscillation involves low values for the primary site and high values for the secondary site for at least 8 of the 10 phases. Secondary oscillation is the opposite pattern. Table 1 shows data for 139 subjects with 10 phases of alternation.

Factor analysis is a multivariate statistical procedure which has been useful in behavioral science; it has been used for exploratory purposes and to

Table 1

Means (M) and Variances (V) for 10 Phases

\begin{tabular}{|c|c|c|c|c|c|c|c|c|c|c|c|}
\hline & & 1 & 2 & 3 & 4 & 5 & 6 & 7 & 8 & 9 & 10 \\
\hline \multicolumn{12}{|c|}{ Latency } \\
\hline $139 \mathrm{Ss}$ & $\begin{array}{l}\text { M } \\
\text { V }\end{array}$ & $\begin{array}{r}9.0 \\
28.0\end{array}$ & $\begin{array}{l}10.0 \\
40.9\end{array}$ & $\begin{array}{r}7.7 \\
30.6\end{array}$ & $\begin{array}{r}9.5 \\
32.9\end{array}$ & $\begin{array}{r}7.8 \\
30.0\end{array}$ & $\begin{array}{r}9.2 \\
32.9\end{array}$ & $\begin{array}{r}8.0 \\
33.7\end{array}$ & $\begin{array}{r}9.1 \\
34.1\end{array}$ & $\begin{array}{r}7.7 \\
32.7\end{array}$ & $\begin{array}{r}8.5 \\
34.1\end{array}$ \\
\hline 59 POs & $\begin{array}{l}\text { M } \\
\text { V }\end{array}$ & $\begin{array}{r}6.8 \\
11.3\end{array}$ & $\begin{array}{l}12.5 \\
36.0\end{array}$ & $\begin{array}{l}5.3 \\
6.3\end{array}$ & $\begin{array}{l}12.1 \\
26.8\end{array}$ & $\begin{array}{r}5.6 \\
10.7\end{array}$ & $\begin{array}{l}12.4 \\
27.7\end{array}$ & $\begin{array}{r}5.7 \\
14.3\end{array}$ & $\begin{array}{l}12.4 \\
27.8\end{array}$ & $\begin{array}{r}5.4 \\
14.4\end{array}$ & $\begin{array}{l}11.1 \\
36.0\end{array}$ \\
\hline 44 SOs & $\begin{array}{l}\text { M } \\
\text { V }\end{array}$ & $\begin{array}{l}11.5 \\
30.5\end{array}$ & $\begin{array}{r}7.7 \\
44.6\end{array}$ & $\begin{array}{l}11.4 \\
45.1\end{array}$ & $\begin{array}{r}7.2 \\
29.3\end{array}$ & $\begin{array}{l}11.6 \\
43.3\end{array}$ & $\begin{array}{r}6.5 \\
20.6\end{array}$ & $\begin{array}{l}11.5 \\
39.7\end{array}$ & $\begin{array}{r}6.4 \\
23.1\end{array}$ & $\begin{array}{l}11.1 \\
40.8\end{array}$ & $\begin{array}{r}6.5 \\
23.9\end{array}$ \\
\hline 31 NOs & $\begin{array}{l}\text { M } \\
\text { V }\end{array}$ & $\begin{array}{l}10.1 \\
39.3\end{array}$ & $\begin{array}{r}9.1 \\
29.0\end{array}$ & $\begin{array}{r}7.4 \\
29.4\end{array}$ & $\begin{array}{r}8.5 \\
30.4\end{array}$ & $\begin{array}{r}7.0 \\
20.6\end{array}$ & $\begin{array}{r}7.4 \\
26.5\end{array}$ & $\begin{array}{r}7.6 \\
37.3\end{array}$ & $\begin{array}{r}6.9 \\
25.2\end{array}$ & $\begin{array}{r}7.5 \\
33.6\end{array}$ & $\begin{array}{r}6.9 \\
25.6\end{array}$ \\
\hline $139 \mathrm{Ss}$ & $\begin{array}{l}\text { M } \\
\text { V }\end{array}$ & $\begin{array}{r}18.6 \\
157.9\end{array}$ & $\begin{array}{r}17.2 \\
124.6\end{array}$ & $\begin{array}{r}7.7 \\
10.2\end{array}$ & $\begin{array}{r}\text { Criter } \\
8.7 \\
20.2\end{array}$ & $\begin{array}{l}7.3 \\
3.7\end{array}$ & $\begin{array}{r}7.4 \\
5.4\end{array}$ & $\begin{array}{l}7.3 \\
5.1\end{array}$ & $\begin{array}{l}7.0 \\
3.1\end{array}$ & $\begin{array}{l}7.2 \\
7.0\end{array}$ & $\begin{array}{l}6.9 \\
2.5\end{array}$ \\
\hline 28 POs & $\begin{array}{l}\text { M } \\
\text { V }\end{array}$ & $\begin{array}{l}12.3 \\
47.6\end{array}$ & $\begin{array}{r}22.0 \\
114.6\end{array}$ & $\begin{array}{r}6.6 \\
.6\end{array}$ & $\begin{array}{l}12.1 \\
51.6\end{array}$ & $\begin{array}{r}6.6 \\
.7\end{array}$ & $\begin{array}{l}10.1 \\
11.1\end{array}$ & $\begin{array}{r}6.4 \\
.6\end{array}$ & $\begin{array}{l}9.0 \\
4.6\end{array}$ & $\begin{array}{r}6.4 \\
.6\end{array}$ & $\begin{array}{l}8.9 \\
3.7\end{array}$ \\
\hline $23 \mathrm{SOs}$ & $\begin{array}{l}\text { M } \\
\text { V }\end{array}$ & $\begin{array}{r}28.4 \\
113.5\end{array}$ & $\begin{array}{l}10.8 \\
33.4\end{array}$ & $\begin{array}{l}12.0 \\
28.9\end{array}$ & $\begin{array}{l}7.0 \\
1.4\end{array}$ & $\begin{array}{l}9.4 \\
4.3\end{array}$ & $\begin{array}{l}6.6 \\
1.0\end{array}$ & $\begin{array}{l}10.6 \\
10.9\end{array}$ & $\begin{array}{l}6.6 \\
1.5\end{array}$ & $\begin{array}{l}10.9 \\
20.1\end{array}$ & $\begin{array}{r}6.3 \\
.5\end{array}$ \\
\hline 85 NOs & $\begin{array}{l}\mathbf{M} \\
\mathbf{V}\end{array}$ & $\begin{array}{r}18.1 \\
172.8\end{array}$ & $\begin{array}{r}17.0 \\
135.3\end{array}$ & $\begin{array}{l}6.8 \\
2.5\end{array}$ & $\begin{array}{r}7.9 \\
10.5\end{array}$ & $\begin{array}{l}6.9 \\
3.1\end{array}$ & $\begin{array}{l}6.7 \\
1.9\end{array}$ & $\begin{array}{l}6.7 \\
1.8\end{array}$ & $\begin{array}{l}6.5 \\
1.5\end{array}$ & $\begin{array}{l}6.5 \\
1.7\end{array}$ & $\begin{array}{l}6.5 \\
1.2\end{array}$ \\
\hline \multicolumn{12}{|c|}{ Duration } \\
\hline $139 \mathrm{Ss}$ & $\begin{array}{l}\mathrm{M} \\
\mathrm{V}\end{array}$ & $\begin{array}{l}22.6 \\
42.1\end{array}$ & $\begin{array}{l}25.1 \\
49.9\end{array}$ & $\begin{array}{l}24.4 \\
33.2\end{array}$ & $\begin{array}{l}24.7 \\
50.8\end{array}$ & $\begin{array}{l}25.3 \\
39.0\end{array}$ & $\begin{array}{l}25.6 \\
39.9\end{array}$ & $\begin{array}{l}25.1 \\
52.1\end{array}$ & $\begin{array}{l}25.7 \\
53.7\end{array}$ & $\begin{array}{l}24.7 \\
46.5\end{array}$ & $\begin{array}{l}25.5 \\
59.6\end{array}$ \\
\hline 37 POs & $\begin{array}{l}\mathbf{M} \\
\mathbf{V}\end{array}$ & $\begin{array}{l}21.6 \\
53.6\end{array}$ & $\begin{array}{l}27.0 \\
50.3\end{array}$ & $\begin{array}{l}22.7 \\
46.0\end{array}$ & $\begin{array}{l}28.8 \\
59.4\end{array}$ & $\begin{array}{l}23.5 \\
31.5\end{array}$ & $\begin{array}{l}29.1 \\
46.1\end{array}$ & $\begin{array}{l}23.4 \\
62.1\end{array}$ & $\begin{array}{l}29.7 \\
62.7\end{array}$ & $\begin{array}{l}21.4 \\
26.6\end{array}$ & $\begin{array}{l}28.6 \\
72.7\end{array}$ \\
\hline $25 \mathrm{SOs}$ & $\begin{array}{l}\text { M } \\
\text { V }\end{array}$ & $\begin{array}{l}23.6 \\
44.8\end{array}$ & $\begin{array}{l}20.8 \\
55.0\end{array}$ & $\begin{array}{l}24.6 \\
26.7\end{array}$ & $\begin{array}{l}18.8 \\
25.9\end{array}$ & $\begin{array}{l}25.2 \\
24.0\end{array}$ & $\begin{array}{l}20.4 \\
18.2\end{array}$ & $\begin{array}{l}25.7 \\
12.6\end{array}$ & $\begin{array}{l}19.7 \\
38.8\end{array}$ & $\begin{array}{l}27.1 \\
70.0\end{array}$ & $\begin{array}{l}20.6 \\
21.8\end{array}$ \\
\hline 68 NOs & $\begin{array}{l}\text { M } \\
\text { V }\end{array}$ & $\begin{array}{l}22.4 \\
32.1 \\
\end{array}$ & $\begin{array}{l}25.3 \\
42.3 \\
\end{array}$ & $\begin{array}{l}25.1 \\
27.1 \\
\end{array}$ & $\begin{array}{l}24.0 \\
33.3 \\
\end{array}$ & $\begin{array}{l}26.1 \\
41.3 \\
\end{array}$ & $\begin{array}{l}25.2 \\
26.4 \\
\end{array}$ & $\begin{array}{l}25.5 \\
49.8 \\
\end{array}$ & $\begin{array}{l}26.1 \\
53.7 \\
\end{array}$ & $\begin{array}{l}25.1 \\
34.6 \\
\end{array}$ & $\begin{array}{l}25.5 \\
48.1 \\
\end{array}$ \\
\hline
\end{tabular}


confirm hypotheses. In the present study, we attempted to use factor analysis for the first purpose; our goal was to determine the factor structure which best accounts for the behavior of kindled Wistar rats over 10 phases of sequential alternation.

\section{METHOD}

The data from previous experiments were used. In each experiment, male Wistar rats were implanted bilaterally in the amygdalae with bipolar electrodes (Nichrome wire with trimel coating, $.127 \mathrm{~mm}$ in diameter, dipped one time in Epoxylite, heated $1 \mathrm{~h}$ at $60^{\circ} \mathrm{C}$ ). The brain coordinates for electrode implantation were the same as in previous experiments: $.5 \mathrm{~mm}$ posterior to bregma, $4.5 \mathrm{~mm}$ from midline, $8.5 \mathrm{~mm}$ from skull (Gaito \& Gaito, 1974). Seven or more days after surgery, brain stimulation was begun.

The stimulation procedure with most rats was the following. Each was stimulated three times each day by a sine wave of $100 \mu \mathrm{A}$ intensity for $30 \mathrm{sec}$ from a Lafayette stimulator. After achieving a criterion of $6 \mathrm{CC}$ with this primary site, stimulation of the contralateral amygdala (secondary site) was begun the next day, using the same procedure, and continued until $6 \mathrm{CC}$ occurred. On the following day, stimulation was begun at the primary site again and was maintained until the criterion of $6 \mathrm{CC}$ was achieved. This alternating procedure continued over 10 of these phases, each involving $6 \mathrm{CC}$.

Most rats were between 135 and 200 days of age at the beginning of each experiment. However, in one study, aged rats (420 to 475 days of age) were used. Likewise, there were deviations from the usual procedure with a few rats in each experiment. For example, some rats were stimulated 1 or 6 times per day; some had 1 or $12 \mathrm{CC}$ to criterion; some animals received 280 and some $560 \mu \mathrm{A}$ stimulation intensities.

In the first study, histological analyses were completed on 13 of the 19 rats involved and indicated that the electrode tips were in both amygdalae in 11 of the 13 rats. However, oscillation resulted whether electrodes were in the amygdalae or in nearby tissue; therefore, histological analyses were not conducted in later experiments.

The data used for the present study were from 139 rats which had been stimulated over 10 or more phases of sequential alternation. The data for 10 phases with three dependent variables were analyzed: latency (time from onset of stimulation to onset of convulsion), criterion (number of trials to $6 \mathrm{CC}$ ), and duration of convulsion (time from onset of forelimb convulsion to complete cessation of convulsion).

In undertaking to determine common factors underlying a set of intercorrelations, it is necessary to insert communalities (proportion of common factor variance) in the main diagonal of the intercorrelation matrix. Unfortunately, these values usually are not available in exact form. Thus, the researcher must estimate them. In the present study, we decided to begin with a principal components analysis using $1 \mathrm{~s}$ in each diagonal. This allows for $\mathrm{k}$ factors to be extracted if $\mathbf{k}$ variables are involved. However, each successive factor extracts maximum variance and many of the later of the $\mathrm{k}$ factors are trivial. The screen test and characteristic roots $\geqslant 1$ were used as criteria to determine the number of significant factors present. These criteria provide better results than that using a chi-square test of correlation matrix residuals after each factor extraction; this latter procedure tends to overestimate the number of factors (Gorsuch, 1974).

Principal axes analyses were performed also in which $\mathbf{R}^{2}$ (multiple correlation squared) and the highest correlation ( $r$ ) of each phase were used as estimates of communality. Therefore, there were three analyses performed to determine the factors present for each of the three dependent variables. Another factor analysis was conducted over the three dependent variables (i.e., 30 phases), using a principal components solution with the screen test and characteristic roots criteria. Product moment correlation coefficients were obtained over the 10 phases for each factor analysis and for intercorrelations between the three dependent variables. All computations were performed on an IBM computer 370 using an APL system at York University.

\section{RESULTS}

The various results are shown in Tables 1 to 9 . Table 1 indicates that the number of oscillators is greatest in the latency measure and least in criterion data.

\section{Means, Variances}

Table 1 shows means and variances for 139 subjects, and for primary oscillators (PO), secondary oscillators (SO), and nonoscillators (NO) within each of the three dependent variables. There was a tendency for means and variances to follow the same oscillation pattern in some of the data. For example, in latency data, for both 139 subjects and for the POs, means and variances oscillate in the "low, high" pattern. Such was not the case for the SOs and NOs.

Phases 1 and 2 show the greatest variances in criterion data. In latency and criterion data, Phases 3, 5, 7, and 9 variances tend to be similar, as is the case with Phases $4,6,8$, and 10 variances. The variances are extremely low for the "low" side for both POs and SOs in criterion data during the later phases.

\section{Intercorrelations}

Tables 2 to 4 show the correlations between phases. In latency data (Table 2 ), the coefficients are all positive. The correlation between Phases 1 and 2 tends to be small or moderate (except for the $\mathbf{3 1}$ NOs), indicating little or no relationship between behavior on Phase 1 and on Phase 2. Also there is the tendency for the correlation between phases on the same side (e.g., 1-3, 1-5, 2-4, 2-6, etc.) to be higher than that between phases on different sides for the 139 subjects. This tendency involves an alternation of values ("low-high") in the table. However, it is not present for the POs, SOs, and NOs.

In criterion data (Table 3), both positive and negative coefficients occur. The correlation between Phases 1 and 2 is zero, except for the POs, where it is moderate. Again, there is the pattern in which correlations are different for the same-side phases than for different-side phases. For example, the relationship of odd to odd numbers and even to even numbers is of positive nature, whereas the others (odd-even and even-odd) tend to be of negative nature. Also, the correlation of Phase 1 and other odd phases and Phase 2 and other even phases tends to be lower than the correlation between similar phases after Phase 2 . This result suggests greater stability in this behavioral variable beginning with 
Table 2

Intercorrelations Between 10 Phases for Latency Measure

\begin{tabular}{|c|c|c|c|c|c|c|c|c|c|c|c|}
\hline & & 1 & 2 & 3 & 4 & 5 & 6 & 7 & 8 & 9 & 10 \\
\hline $\begin{array}{c}59 \text { POs } \\
(.257)\end{array}$ & $\begin{array}{r}1 \\
2 \\
3 \\
4 \\
5 \\
6 \\
7 \\
8 \\
9 \\
10\end{array}$ & $\begin{array}{l}294 \\
284 \\
369 \\
293 \\
307 \\
332 \\
418 \\
231 \\
305\end{array}$ & $\begin{array}{l}239 \\
\\
148 \\
758 \\
162 \\
612 \\
213 \\
358 \\
172 \\
335\end{array}$ & $\begin{array}{l}539 \\
318 \\
\\
417 \\
782 \\
470 \\
687 \\
455 \\
641 \\
467\end{array}$ & $\begin{array}{l}254 \\
851 \\
393 \\
\\
392 \\
834 \\
426 \\
579 \\
425 \\
490\end{array}$ & $\begin{array}{l}139 \\
533 \\
311 \\
891 \\
391 \\
\\
519 \\
864 \\
495 \\
847 \\
426\end{array}$ & $\begin{array}{l}167) \\
127 \\
713 \\
308 \\
879 \\
359 \\
\\
566 \\
736 \\
532 \\
736\end{array}$ & $\begin{array}{l}519 \\
222 \\
816 \\
371 \\
890 \\
393 \\
\\
542 \\
861 \\
478\end{array}$ & $\begin{array}{l}131 \\
594 \\
267 \\
750 \\
327 \\
860 \\
368 \\
\\
506 \\
779\end{array}$ & $\begin{array}{l}470 \\
238 \\
755 \\
370 \\
853 \\
357 \\
889 \\
379 \\
481\end{array}$ & $\begin{array}{l}152 \\
566 \\
332 \\
694 \\
377 \\
840 \\
393 \\
878 \\
403\end{array}$ \\
\hline $\begin{array}{c}31 \mathrm{NOs} \\
(.356)\end{array}$ & $\begin{array}{r}1 \\
2 \\
3 \\
4 \\
5 \\
6 \\
7 \\
8 \\
9 \\
10\end{array}$ & $\begin{array}{r}560 \\
160 \\
509 \\
083 \\
171 \\
117 \\
-033 \\
010 \\
-009\end{array}$ & $\begin{array}{l}384 \\
\\
396 \\
760 \\
523 \\
497 \\
324 \\
421 \\
432 \\
344\end{array}$ & $\begin{array}{l}559 \\
810 \\
\\
678 \\
861 \\
871 \\
790 \\
673 \\
675 \\
721\end{array}$ & $\begin{array}{l}448 \\
920 \\
868 \\
\\
804 \\
796 \\
668 \\
608 \\
684 \\
579\end{array}$ & $\begin{array}{l}44 \mathrm{SC} \\
589 \\
763 \\
878 \\
835 \\
\\
969 \\
882 \\
820 \\
793 \\
833\end{array}$ & $\begin{array}{l}298) \\
497 \\
777 \\
745 \\
908 \\
831 \\
\\
902 \\
778 \\
787 \\
844\end{array}$ & $\begin{array}{l}584 \\
536 \\
778 \\
715 \\
862 \\
783 \\
\\
801 \\
810 \\
841\end{array}$ & $\begin{array}{l}548 \\
700 \\
710 \\
855 \\
789 \\
915 \\
788 \\
\\
886 \\
923\end{array}$ & $\begin{array}{l}543 \\
557 \\
696 \\
702 \\
808 \\
763 \\
872 \\
824 \\
839\end{array}$ & $\begin{array}{l}492 \\
538 \\
702 \\
854 \\
811 \\
894 \\
713 \\
939 \\
747\end{array}$ \\
\hline
\end{tabular}

Note-decimals omitted. In parentheses are the values of coefficients required to reject the null hypothesis of zero correlations at .05 probability level.

Phase 3. This aspect is reflected also in Table 1, where the variances tend to be greater for Phases 1 and 2 than for later phases.

In the duration measure, the coefficients are all positive except one for the 139 subjects and a number for the SOs. For the former it is interesting to note that the correlations tend to be more homogeneous, especially for adjacent phases, than those for the 139 subjects in latency and criterion data wherein an alternating pattern of "low-high" or "positivenegative" occurs for a series of correlations. For example, for latency data, the correlation of Phase 1 with Phase 2 , Phase 3, etc., follows both the "highlow" and "positive-negative" patterns. One or both

Table 3

Intercorrelations Between 10 Phases for Criterion Measure

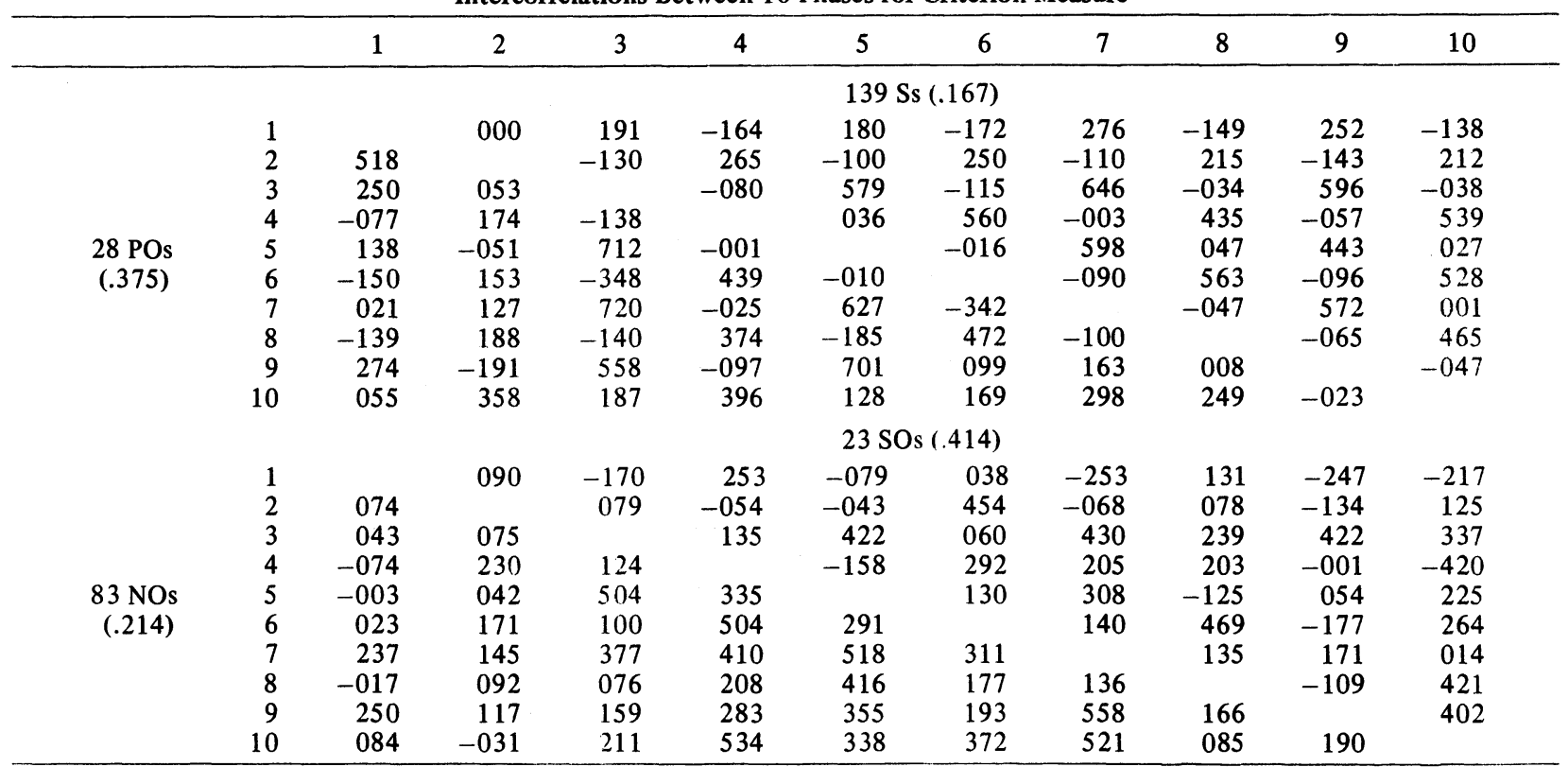

Note-decimals omitted. In parenthesis are the values of coefficients required to reject the null hypothesis of zero correlations at .05 probability level. 
Table 4

Intercorrelations Between 10 Phases for Duration Measure

\begin{tabular}{|c|c|c|c|c|c|c|c|c|c|c|c|}
\hline & & 1 & 2 & 3 & 4 & 5 & 6 & 7 & 8 & 9 & 10 \\
\hline \multicolumn{12}{|c|}{139 Ss (.167) } \\
\hline \multirow[t]{2}{*}{$\begin{array}{c}37 \text { POs } \\
(.372)\end{array}$} & $\begin{array}{r}1 \\
2 \\
3 \\
4 \\
5 \\
6 \\
7 \\
8 \\
9 \\
10\end{array}$ & $\begin{array}{l}782 \\
602 \\
602 \\
362 \\
317 \\
224 \\
366 \\
119 \\
023\end{array}$ & $\begin{array}{l}466 \\
\\
697 \\
735 \\
428 \\
404 \\
204 \\
319 \\
383 \\
117\end{array}$ & $\begin{array}{l}336 \\
516 \\
\\
709 \\
550 \\
622 \\
538 \\
444 \\
412 \\
402\end{array}$ & $\begin{array}{l}259 \\
616 \\
437 \\
\\
444 \\
639 \\
470 \\
542 \\
469 \\
304\end{array}$ & $\begin{array}{l}167 \\
407 \\
565 \\
382 \\
\\
583 \\
432 \\
511 \\
432 \\
507\end{array}$ & $\begin{array}{l}175 \\
412 \\
416 \\
601 \\
384 \\
\\
506 \\
619 \\
654 \\
637\end{array}$ & $\begin{array}{l}151 \\
305 \\
511 \\
356 \\
600 \\
295 \\
\\
411 \\
252 \\
575\end{array}$ & $\begin{array}{l}131 \\
322 \\
376 \\
496 \\
384 \\
592 \\
298 \\
\\
441 \\
317\end{array}$ & $\begin{array}{l}060 \\
053 \\
382 \\
168 \\
450 \\
264 \\
446 \\
322 \\
\\
377\end{array}$ & $\begin{array}{r}-007 \\
341 \\
367 \\
454 \\
514 \\
664 \\
448 \\
477 \\
238\end{array}$ \\
\hline & & \multicolumn{10}{|c|}{25 SOs (.381) } \\
\hline $\begin{array}{c}68 \text { NOs } \\
(.236)\end{array}$ & $\begin{array}{r}1 \\
2 \\
3 \\
4 \\
5 \\
6 \\
7 \\
8 \\
9 \\
10\end{array}$ & $\begin{array}{l}465 \\
230 \\
346 \\
195 \\
255 \\
273 \\
225 \\
174 \\
048\end{array}$ & $\begin{array}{l}426 \\
\\
536 \\
605 \\
616 \\
403 \\
412 \\
283 \\
127 \\
419\end{array}$ & $\begin{array}{l}045 \\
474 \\
\\
501 \\
631 \\
510 \\
457 \\
480 \\
362 \\
395\end{array}$ & $\begin{array}{l}067 \\
171 \\
384 \\
\\
686 \\
455 \\
484 \\
372 \\
309 \\
404\end{array}$ & $\begin{array}{r}-065 \\
-150 \\
102 \\
-233 \\
\\
369 \\
609 \\
389 \\
290 \\
572\end{array}$ & $\begin{array}{r}032 \\
-074 \\
120 \\
181 \\
586 \\
\\
284 \\
398 \\
291 \\
546\end{array}$ & $\begin{array}{l}119 \\
309 \\
606 \\
158 \\
536 \\
350 \\
\\
345 \\
391 \\
452\end{array}$ & $\begin{array}{r}-269 \\
-143 \\
340 \\
079 \\
528 \\
546 \\
447 \\
\\
508 \\
286\end{array}$ & $\begin{array}{r}-150 \\
-339 \\
271 \\
152 \\
584 \\
647 \\
574 \\
689\end{array}$ & $\begin{array}{r}-059 \\
-074 \\
345 \\
170 \\
563 \\
610 \\
510 \\
784 \\
690\end{array}$ \\
\hline
\end{tabular}

Note-Decimals omitted. In parentheses are the values of coefficients required to reject the null hypothesis of zero correlation at .05 probability level.

of these patterns occur throughout this table and for the criterion measure as well. Such patterning does not occur for the duration measure.

This difference between duration and latencycriterion results probably accounts for the appearance of one common factor for the former and two factors for the latter pair (see below).

Another interesting difference between duration and the latency-criterion measures is the magnitude of the correlation coefficient for Phases 1 and 2 . The coefficient for duration is higher (.466) than for latency (.239) and criterion (.000). This result is consistent with the statement concerning the greater homogeneity within the duration measure.

For the latency measure, all four sets of coefficients are positive. Only a few are not significantly different from zero (at probability level of $.05)$, viz., the correlations of Phase 1 with some others, the correlation of Phase 2 with some others. Phases 1 and 2 are the most variable ones.

In the criterion and duration measures, fewer correlation coefficients were significantly different from zero (except for the 139 subjects' data).
Table 5 indicates the intercorrelations between the three dependent variables over the 10 phases. The correlations between latency and criterion for each phase are all significantly different from zero. Higher correlations consistently occur for the phases corresponding to primary site stimulation after Phases 1 and 2; the series of correlations follow a "high-low" pattern over these phases. The coefficients are greater on Phases 3, 5, 7, and 9 (of moderate magnitude) than on Phase 1 (just barely significant); Phases 2, 4, 6, 8, and 10 all are of low magnitude. The greatest $\mathrm{r}$ for the primary site is .542 (Phase 7); the highest value for the secondary site is $\mathbf{. 3 4 6}$ (Phase 6). On the other hand, of the 20 correlations involving duration, only 7 are significant, 2 for latency-duration relationships and 5 for criterionduration relationships. These results suggest that the latency-criterion dependent variables are different from the duration measure, as has been pointed out by Burnham (1975).

\section{Factor Analyses}

The factor extraction data are presented in Tables 6-

Table 5

Intercorrelations Between Latency (L), Criterion (C), and Duration (D) Measures for the 139 Subjects

\begin{tabular}{|c|c|c|c|c|c|c|c|c|c|c|}
\hline & \multicolumn{10}{|c|}{ Phases } \\
\hline & 1 & 2 & 3 & 4 & 5 & 6 & 7 & 8 & 9 & 10 \\
\hline $\begin{array}{l}\text { L-C } \\
\text { L-D } \\
\text { C-D }\end{array}$ & $\begin{array}{r}.198 \\
-.132 \\
-.182\end{array}$ & $\begin{array}{r}.242 \\
-.045 \\
.031\end{array}$ & $\begin{array}{l}.456 \\
.141 \\
.151\end{array}$ & $\begin{array}{l}.243 \\
.150 \\
.183\end{array}$ & $\begin{array}{l}.500 \\
.194 \\
.226\end{array}$ & $\begin{array}{l}.346 \\
.198 \\
.226\end{array}$ & $\begin{array}{l}.542 \\
.142 \\
.444\end{array}$ & $\begin{array}{l}.291 \\
.154 \\
.022\end{array}$ & $\begin{array}{l}.437 \\
.043 \\
.123\end{array}$ & $\begin{array}{l}.290 \\
.025 \\
.030\end{array}$ \\
\hline
\end{tabular}

Note- .167 is the value required to reject the null hypothesis of zero correlation at .05 probability level. 
Table 6

Factor Loadings for Latency Measure (139 Subjects)

\begin{tabular}{ccccccc}
\hline & \multicolumn{3}{c}{ Unrotated Factors (F) } & & \multicolumn{2}{c}{$\begin{array}{c}\text { Rotated } \\
\text { Factors (Fr) }\end{array}$} \\
\cline { 2 - 3 } \cline { 6 - 7 } Phases & $\mathrm{A}$ & $\mathrm{B}$ & $\mathrm{h}^{2}$ & & $\mathrm{~A}$ & $\mathrm{~B}$ \\
\hline 1 & .500 & .452 & .454 & -.001 & .674 \\
2 & .678 & -.458 & .669 & .794 & .198 \\
3 & .752 & .523 & .839 & .114 & .909 \\
4 & .806 & -.455 & .857 & .877 & .295 \\
5 & .797 & .527 & .913 & .141 & .945 \\
6 & .798 & -.530 & .918 & .928 & .238 \\
7 & .789 & .517 & .890 & .144 & .932 \\
8 & .759 & -.505 & .831 & .883 & .226 \\
9 & .770 & .485 & .828 & .155 & .896 \\
10 & .769 & -.442 & .787 & .842 & .275 \\
CP & .558 & .799 & & & \\
\hline
\end{tabular}

Note-Fr $=F T$, where $T$ is transformation matrix for 48-deg rotation clockwise,

$$
\left|\begin{array}{cc}
\cos \Theta & \sin \Theta \\
-\sin \Theta & \cos \Theta
\end{array}\right|=\left|\begin{array}{rr}
.669 & .743 \\
-.743 & .669
\end{array}\right|
$$

$h^{2}$ is communality (sum of squared factor loadings - proportion of common factor variance); and $C P$ is cumulative proportion of variance extracted.

9. Three methods were used with each dependent variable: principal components (with $1 \mathrm{~s}$ in the main diagonal), principal axes with the highest $r$ in the diagonal, principal axes with $\mathbf{R}^{2}$ (multiple correlation coefficient squared) in the diagonal (Gorsuch, 1974). The three methods provided similar results for the significant factors, with slightly lower factor loadings for the two principal axes solutions. Only the principal components values are shown in Tables 6-9.

Two criteria were used to differentiate significant factors from trivial ones: characteristic roots $\geqslant 1$ and the scree test (Gorsuch, 1974). The latter test involves plotting the characteristic roots or eigen values for the 10 phases. The characteristic roots for trivial factors are in a straight line, whereas those for significant factors show a sharp break or cliff effect. Two factors were indicated each for the latency and criterion measures and one for duration.

Factor extraction provides an ambiguous solution because the axes are arbitrary. Thus, orthogonal rotation procedures were used to provide a solution easy to interpret with latency and criterion data. With only two factors present, the rotation problem is simplified and can be done visually. Thus, the factor loadings (two-dimensional coordinates) were plotted to give the unrotated results shown in Figures 1 and 2 . The axes were rotated to a position which involved each factor axis passing through or near a cluster, as indicated in Figures 1 and 2. The original factor loadings were transformed (via the transformation matrix in each table) to the final factor loadings in Tables 6 and 7. With only one factor indicated for the duration measures, no rotation is required.

Figure 1 shows the original and rotated factor

Table 7

Factor Loadings for Criterion Measure (139 Subjects)

\begin{tabular}{lrrrrrr}
\hline & \multicolumn{3}{c}{} & & \multicolumn{2}{c}{$\begin{array}{c}\text { Rotated } \\
\text { Enctors (Fr) }\end{array}$} \\
\cline { 2 - 4 } \cline { 6 - 7 } Phases & $\mathrm{A}$ & $\mathrm{B}$ & $\mathrm{h}^{2}$ & & $\mathrm{~A}$ & $\mathrm{~B}$ \\
\hline 1 & .438 & .039 & .193 & .347 & -.271 \\
2 & -.382 & .227 & .197 & -.124 & .427 \\
3 & .701 & .474 & .716 & .835 & -.132 \\
4 & -.491 & .623 & .629 & .066 & .790 \\
5 & .576 & .540 & .623 & .789 & .002 \\
6 & -.564 & .603 & .682 & -.001 & .826 \\
7 & .687 & .515 & .737 & .853 & -.093 \\
8 & -.466 & .595 & .571 & .065 & .753 \\
9 & .663 & .422 & .618 & .773 & -.144 \\
10 & -.464 & .627 & .608 & .089 & .774 \\
CP & .306 & .557 & & & \\
\hline
\end{tabular}

Note-Fr $=F T$, where $T$ is transformation matrix for 43-deg rotation clockwise,

$$
\left|\begin{array}{rr}
\cos \Theta & -\sin \Theta \\
-\sin \Theta & \cos \Theta
\end{array}\right|=\left|\begin{array}{rr}
.731 & -.682 \\
.628 & .731
\end{array}\right|,
$$

and $C P$, cumulative proportion of variance extracted.

Table 8

\begin{tabular}{|c|c|c|c|c|c|c|c|c|c|}
\hline \multirow[b]{2}{*}{ Phases } & \multicolumn{3}{|c|}{ POs } & \multicolumn{3}{|c|}{ SOs } & \multicolumn{3}{|c|}{ NOs } \\
\hline & A & B & $\mathrm{h}^{2}$ & A & B & $\mathrm{h}^{2}$ & A & B & $h^{2}$ \\
\hline 1 & .478 & .179 & .261 & .626 & .594 & .745 & .439 & .826 & .875 \\
\hline 2 & .515 & .676 & .722 & .828 & -.435 & .875 & .719 & .557 & .829 \\
\hline 3 & .740 & -.394 & .703 & .887 & -.054 & .790 & .890 & -.074 & .798 \\
\hline 4 & .758 & .495 & .820 & .934 & -.301 & .963 & .891 & .335 & .906 \\
\hline 5 & .805 & -.495 & .893 & .936 & .058 & .879 & .969 & -.085 & .946 \\
\hline 6 & .860 & .344 & .858 & .935 & -.127 & .890 & .967 & -.069 & .940 \\
\hline 7 & .829 & -.415 & .859 & .874 & .305 & .857 & .917 & -.206 & .883 \\
\hline 8 & .801 & .181 & .674 & .928 & -.004 & .861 & .908 & -.244 & .884 \\
\hline 9 & .797 & -.440 & .829 & .861 & .262 & .810 & .901 & -.212 & .857 \\
\hline 10 & .753 & .172 & .597 & .909 & -.119 & .840 & .911 & -.271 & .903 \\
\hline $\mathrm{CP}$ & .553 & .722 & & .768 & .851 & & .748 & .882 & \\
\hline
\end{tabular}

Unrotated Factor Loadings for the POs, SOs, and NOs in the Latency Measure

Note $-C P=$ cumulative proportion of variance extracted. 
Table 9

Factor Loadings for 139 Subjects Over the Three Dependent Variables, Latency (L), Criterion (C), and Duration (D)

\begin{tabular}{|c|c|c|c|c|c|c|c|}
\hline \multirow[b]{2}{*}{ Phases } & \multicolumn{4}{|c|}{ Unrotated Factors (F) } & \multicolumn{3}{|c|}{ Rotated Factors (Fr) } \\
\hline & $\mathbf{A}$ & B & $\mathrm{C}$ & $\mathrm{h}^{2}$ & $\mathbf{A}$ & B & $\mathrm{C}$ \\
\hline L 1 & .401 & -.425 & -.177 & .373 & .594 & .094 & -.107 \\
\hline L 2 & .514 & .250 & -.528 & .605 & .199 & .751 & -.044 \\
\hline L 3 & .676 & -.511 & -.212 & .763 & .846 & .215 & -.031 \\
\hline L 4 & .629 & .227 & -.575 & .778 & .297 & .829 & -.031 \\
\hline L 5 & .753 & -.487 & -.151 & .827 & .878 & .230 & .064 \\
\hline L 6 & .660 & .332 & -.536 & .833 & .240 & .879 & .057 \\
\hline L 7 & .728 & -.483 & -.181 & .796 & .859 & .238 & .030 \\
\hline L 8 & .656 & .318 & -.441 & .726 & .241 & .808 & .122 \\
\hline L 9 & .746 & -.417 & -.119 & .745 & .820 & .244 & .114 \\
\hline L10 & .653 & .238 & -.460 & .695 & .299 & .775 & .073 \\
\hline C11 & .128 & -.476 & -.013 & .243 & .435 & -.186 & -.140 \\
\hline $\mathrm{C} 12$ & .068 & .293 & -.236 & .146 & -.154 & .349 & -.027 \\
\hline $\mathrm{C} 13$ & .474 & -.477 & .253 & .516 & .656 & -.172 & .237 \\
\hline C14 & .317 & .491 & -.121 & .356 & -.134 & .517 & .267 \\
\hline $\mathrm{C} 15$ & .520 & -.382 & .174 & .447 & .623 & -.045 & .238 \\
\hline $\mathrm{C} 16$ & .269 & .577 & -.188 & .441 & -.226 & .582 & .226 \\
\hline $\mathrm{C} 17$ & .607 & -.474 & .246 & .654 & .745 & -.096 & .299 \\
\hline C18 & .276 & .469 & -.120 & .311 & -.147 & .483 & .238 \\
\hline C19 & ,467 & -.448 & .234 & .474 & .631 & -.148 & .231 \\
\hline $\mathrm{C} 20$ & .332 & .468 & -.087 & .337 & -.109 & .490 & .291 \\
\hline D21 & .306 & .265 & .080 & .170 & .011 & .258 & .322 \\
\hline D22 & .455 & .258 & .415 & .446 & .098 & .118 & .650 \\
\hline D23 & .518 & .262 & .446 & .536 & .136 & .133 & .707 \\
\hline D24 & .510 & .283 & .445 & .538 & .116 & .141 & .711 \\
\hline D25 & .511 & .160 & .528 & .566 & .201 & .021 & .724 \\
\hline D26 & .393 & .428 & .442 & .533 & -.070 & .161 & .709 \\
\hline D27 & .517 & .097 & .494 & .521 & .252 & .011 & .676 \\
\hline D28 & .377 & .302 & .447 & .433 & .011 & .080 & .653 \\
\hline D29 & .287 & .282 & .289 & .245 & -.027 & .122 & .479 \\
\hline D30 & .371 & .226 & .544 & .485 & .056 & -.028 & .693 \\
\hline $\mathrm{CP}$ & .252 & .396 & .518 & & & & \\
\hline
\end{tabular}

Note-Fr $=F T$, where $T$ is transformation matrix,

$\begin{array}{rrr}.682 & .533 & .501 \\ -.729 & .550 & .407 \\ -.059 & -.643 & .764\end{array}$

and $C P=$ cumulative proportion of variance extracted.

solutions for the criterion measure. The angle of rotation is $43^{\circ}$ counterclockwise. There are two clusters: odd-numbered phases, even-numbered phases. In each case, the first phases, i.e., 1 and 2, are slightly removed from the others of the cluster, probably reflecting the greater variability (and thus greater error variance) for these phases than others. The clusters appear to be orthogonal, i.e., at a $90^{\circ}$ angle, or approximately so.

The angle of rotation for latency axes is $48^{\circ}$ clockwise (Figure 2). The rotated solution is similar to that for the latency measure in that two clusters emerge clearly. However, the two clusters are moderately correlated, i.e., each cluster is slightly off the factor axis. Thus, the angle between the axes running through each cluster is approximately $60^{\circ}$. This indicates a correlation of approximately .500 between the two factors. An oblique rotation would have provided a more exact solution than the orthogonal one in this case. However, this step was not necessary inasmuch as the relationship of the two clusters was clear. Phases 1 and 2 are within their respective clusters in contrast to their position in criterion data.

The loadings and communalities for the single factor in the duration measure over the 10 phases were: $.356, .127 ; .670, .449 ; .744, .554 ; .739, .546$; $.746, .557 ; .748, .560 ; .670, .449 ; .677, .458 ; .489$, $.239 ; .712, .507$, respectively. This factor accounted for .445 of the total variance.

The latency measure was a stronger indicator of oscillation than the other measures; thus, the 139 subjects were separated into three categories (PO, $\mathrm{SO}$, NO), and factor analyses were performed on each of these. Because of the small number of subjects in each of these three cases, the factor solutions should be considered merely of a suggestive nature. Two factors were extracted in each case.

Factor loadings for POs, SOs, and NOs are shown in Table 8. A complete orthogonal rotation solution 


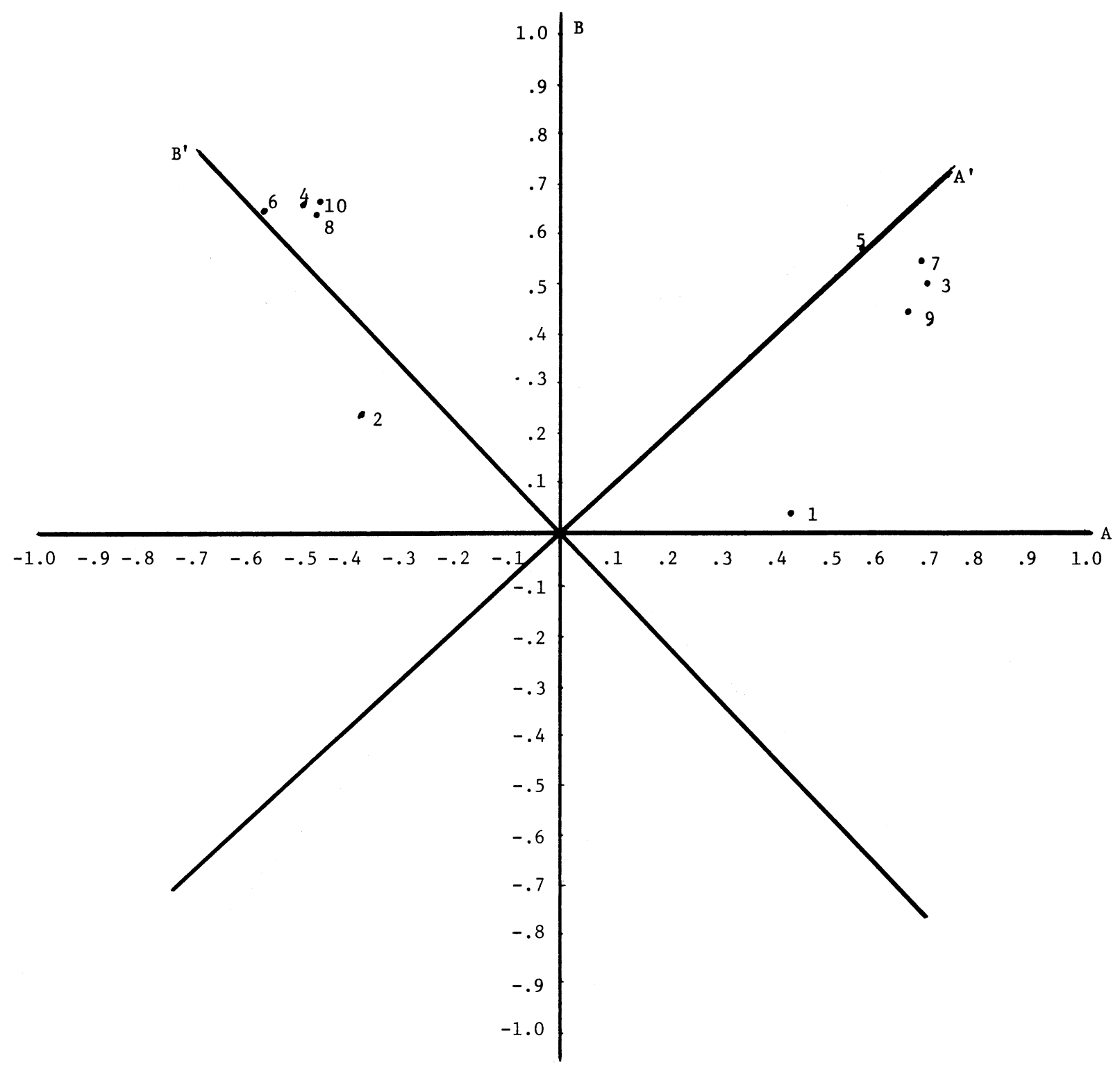

Figure 1. The two clusters of phases for the criterion measure. $A$ and $B$ are original factor axes. $A^{\prime}$ and $B^{\prime}$ are axes after rotation $43^{\circ}$ counterclockwise. $r_{a b}=0, r_{a^{\prime}} b^{\prime}=0$.

was not provided with these three, because the clustering was not as concentrated as with the 139 subjects. There was overlap between the primary site and secondary site phases, especially for the NOs. Phases 3, 5, 7, and 9 were clustered with Phases 6, 8, and 10; Phases 1, 2, and 4 were scattered elsewhere. The pattern for the SOs was a little clearer; the 10 phases were spread in an arc with primary site phases on one side and the secondary site phases on the other part, and Phases 3 and 9 overlapping in the central portion.

The POs gave the best separation of the two sites. Phases 3, 5, 7, and 9 were clustered close together and the other phases were spread in a semicircle. A clockwise rotation of $37^{\circ}$ would have provided a reasonably good solution.

A factor analysis also was conducted for the 139 subjects over the three dependent variables (i.e., 30 phases), using a principle components solution with the scree test and characteristic roots as criteria for determining the number of significant factors. Three factors were extracted and rotated orthogonally using an equimax method. These three factors were indicated to be clearly present, the same ones as those which emerged in the separate analyses, viz., a primary site stimulation factor, A; a secondary site stimulation factor, B; and a duration factor, C (Table 9). Each of the three two-dimensional 


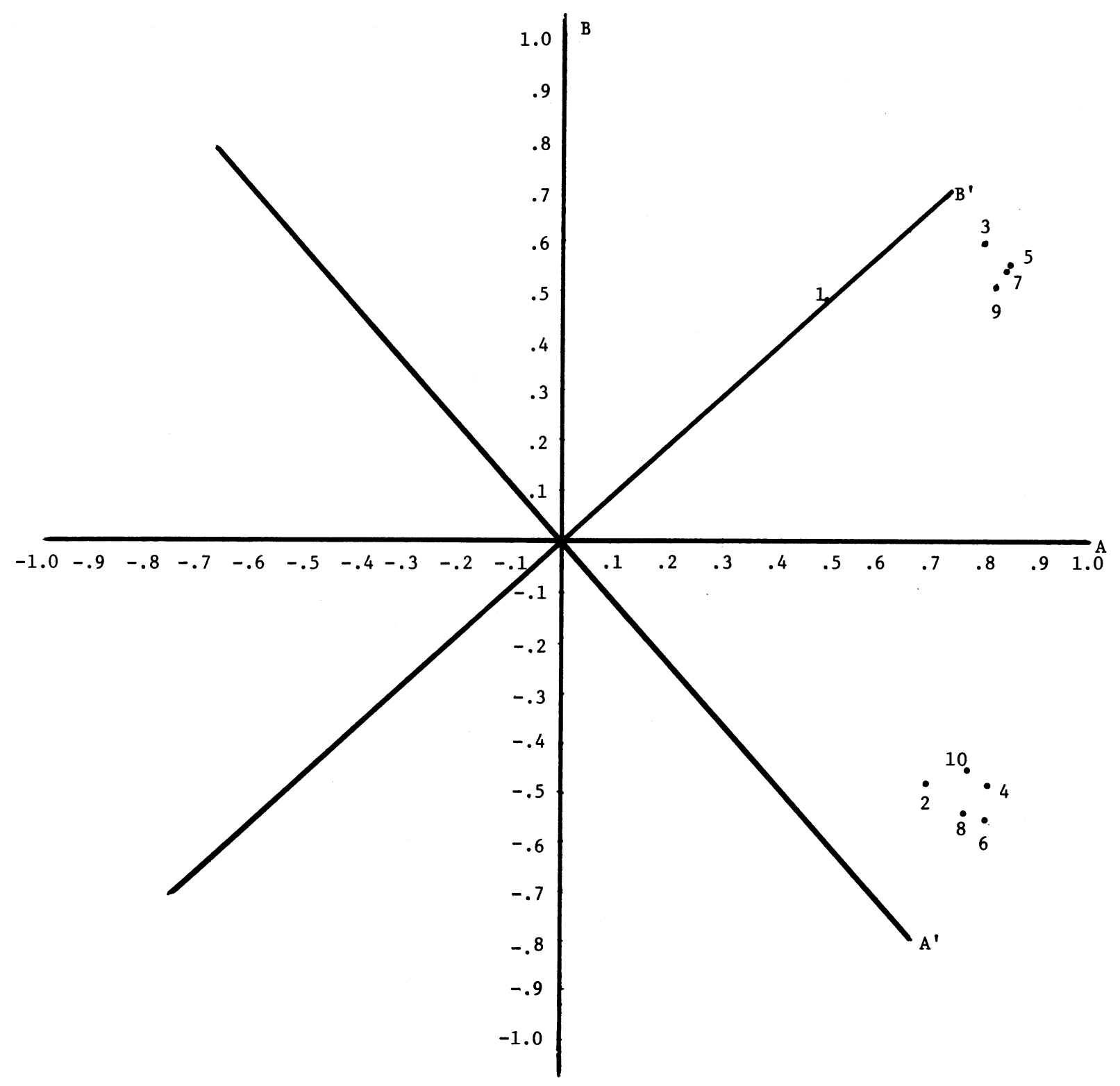

Figure 2. The two clusters of phases for the latency measure. Axes are same as in Figure 1. $\mathbf{r}_{\mathbf{a b}}=0, \mathbf{r}_{\mathbf{a}^{\prime} \mathbf{b}^{\prime}}=0$.

graphs (A, B-A, C-B, C) provided a clear picture of the results. In each graph, the phases representing each of these three factors clustered separately from the other two. One cluster had high loadings on only one factor axis, and another had high loadings on only the second factor axis. The third cluster had loadings around the zero point for factor axes.

\section{DISCUSSION}

There are a number of conclusions which emanate from this study. These are:

(1) The data appear to be more variable for Phases 1 and 2 for the criterion measure, with rela- tive stability seeming to occur first during Phases 3 and 4.

(2) Factor loadings and communalities for Phase 1 tend to be the lowest of the 10 phases for the three measures, indicating a greater proportion of error variance due to the great variability in the beginning trials and/or greater specific variance present.

(3) The factor patterns for the 139 subjects in latency and criterion measures appear to be reasonably clear, two approximately orthogonal factors in the latter case and two moderately correlated factors for the latency data. The phases involving the primary side are clustered separately from those phases in which the secondary side is stimulated. 
Thus, one might call the factor on which Phases 1, 3, 5,7 , and 9 have moderate or high loadings the primary site stimulation factor. The second factor could be designated as the secondary site stimulation factor.

(4) The factor pattern for the duration data is for a single factor.

(5) The latency and criterion measures are similar, but appear different from the duration measure. This statement is supported by the intercorrelations between the three dependent variables, the factor structure determined for each of the three, and the factor structure determined over the 30 phases. These results are consistent with those of Burnham (1975) which lead him to suggest that latency was an indicator of a triggering mechanism, whereas duration values were concerned with a convulsion mechanism.

(6) The factor analysis for the POs, SOs, and NOs in the latency measure appear similar to that for the 139 subjects with factors which may be the same as in the overall analyses seeming to emerge; the appearance of separate stimulation sites was suggested but was not as clear because the clustering was not as concentrated.

These results of two factors in the latency and criterion measures may appear somewhat different from the two factors (or effects) of Goddard et al. (1969) and McIntyre and Goddard (1973). Their first factor was a positive transfer one of a long-term nature, and the "aftereffect" (second factor) was a less durable one of a negative transfer nature. However, the "aftereffect" is involved in convulsions from stimulation of both the primary and secondary sites. Thus, the two factors can be viewed as (a) a primary site factor of a neurological trace nature with a residual "aftereffect," and (b) a secondary site factor of a neurological trace nature with a residual "aftereffect." Thus, our two factors are basically the same as the two factors of Goddard et al. and McIntyre and Goddard.

The consistency of the positive transfer aspects in the Goddard et al. formulation occurs for both the primary and secondary sites via neurological trace aspects. In our analyses, the consistency is shown separately in each of our factors. Phases 1, 3, 5, 7, and 9 tend to cluster on one factor and $2,4,6,8$, and 10 on the other, although Phases 1 and 2 remain a little remote from the other phases of each cluster in criterion data. Presumably differential "aftereffects" in the two sites may be the main contribution to the consistent differences in the latency values of primary and secondary sites.

Also, one might relate our factors to the two mechanisms of Burnham (1975); however, there is the obvious difference that we are concerned with stimulation sites, whereas Burnham is concerned with the mechanisms involved. Furthermore, we are concerned with the number of factors within each measure, whereas Burnham's two factors occur over two dependent variables, latency and duration.

If one considers the factor structure over the three dependent variables, it appears that there are three factors (Table 9). One single factor would be the convulsion mechanism of Burnham, inasmuch as duration is the indicator of this mechanism (Burnham, 1975). Our two factors in latency and criterion data would be related to the Burnham triggering mechanism, a triggering mechanism for each of the sides (Table 10).

The negative transfer in latency data occurring consistently in our alternating phases from one specific amygdala to the other one may involve the same mechanism as that found in previous studies in our laboratory in which interanimal retardation resulted during the development of kindling via intraperitoneal injections of brain extracts (Gaito \& Gaito, 1974). If so, the basis for the negative transfer in both cases would involve an inhibitory chemical.

In closing, it should be noted that these factor analysis results are those which are suggested when the means of six convulsion trials are used. The results obtained probably would be more complicated if the data from each of the six trials in each phase were utilized. Likewise, the results probably would be different when either the mean of six trials or the data from each trial were used over 10 phases if stimulation were always on one side only. These type of analyses are anticipated for the near future.

Furthermore, it should be noted that these results apply to subjects which have been exposed to differ-

Table 10

Factors or Mechanisms Present During Sequential Alternation Within the Kindling Paradigm

\begin{tabular}{llll}
\hline $\begin{array}{l}\text { Goddard et al. (1969) } \\
\text { McIntyre-Goddard (1973) }\end{array}$ & Burnham (1975) & Factor Analyses & \multicolumn{1}{c}{$\begin{array}{c}\text { Measures as } \\
\text { Indicators }\end{array}$} \\
\hline $\begin{array}{l}\text { Neurological trace with } \\
\text { aftereffect (primary site) }\end{array}$ & $\begin{array}{l}\text { triggering mechanism } \\
\text { (primary site) }\end{array}$ & $\begin{array}{l}\text { primary site } \\
\text { stimulation factor }\end{array}$ & latency, criterion \\
$\begin{array}{l}\text { Neurological trace with } \\
\text { aftereffect (secondary site) }\end{array}$ & $\begin{array}{l}\text { triggering mechanism } \\
\text { (secondary site) } \\
\end{array}$ & $\begin{array}{l}\text { secondary site } \\
\text { stimulation factor } \\
\text { (both sites) }\end{array}$ & latency, criterion \\
& duration factor & duration \\
\hline
\end{tabular}


ent stimulation conditions, e.g., intensities of stimulation, different number of convulsions per phase, etc. In the future, a study is planned on the results obtained when all subjects are treated the same way in all respects.

\section{REFERENCES}

Burnham, W. M. Primary and "transfer" seizure development in the kindled rat. Canadian Journal of Neurological Sciences, 1975, 2, 417-428.

Garro, J. The kindling effect as a model of epilepsy. Psychological Bulletin, 1976, 83, 1097-1109. (a)

GAITo, J. An oscillation effect during sequential alternations of unilateral amygdaloid stimulations within the kindling paradigm. Physiological Psychology, 1976, 4, 303-306. (b)

GAITO, J. The effect of bilateral stimulation during sequential alternation of unilateral amygdaloid stimulation. Bulletin of the Psychonomic Society, 1976, 4, 355-357. (c)

GaITo, J. The effect of number of trials per day during sequential alternation of unilateral amygdaloid stimulation. Bulletin of the Psychonomic Society, 1976, 4, 403-404. (d)

GaITo, J. The effect of number of convulsions per phase on the oscillation tendency. Bulletin of the Psychonomic Society, 1976, 8, 392-394. (e)

GaIto, J. The effect of varying rest intervals following the development of oscillation during amygdaloid stimulation. Bulletin of the Psychonomic Society, 1976, 8, 457-458. (f)

GAIro, J. The effect of intensity during sequential alternation of unilateral amygdaloid stimulation. Bulletin of the Psychonomic Society, 1977, 9, 64-66.

GaITo, J., \& GaITo, S. T. Interanimal negative transfer of the kindling effect. Physiological Psychology, 1974, 2, 379-382.

GaIto, J., \& Nobrega, J. The oscillation effect during sequential alternation of amygdaloid stimulation with aged rats. Bulletin of the Psychonomic Society, 1977, 9, 151-154.

Goddard, G. V., McIntYre, D. C., \& LEECh, C. K. A permanent change in brain function resulting from daily electrical stimulation. Experimental Neurology, 1969, 25, 295-330.

GoRsuch, R. L. Factor analysis. New York: Saunders, 1974.

MCINTYRE, D. C., \& GodDARD, G. V. Transfer, interference and spontaneous recovery of convulsions kindled from the rat amygdala. Electroencephalography and Clinical Neurophysiology, 1973, 35, 533-543.

(Received for publication July 7, 1976; revision accepted March 25, 1977.) 